\title{
Development of a simulation model for controlling and improving the productivity of batch reactors
}

\author{
Ghania Henini $^{1,2,}$, Fatiha Souahi², Ykhlef Laidani ${ }^{1}$ \\ ${ }^{1}$ Hassiba Ben Bouali University, P.O. Box.151, Hay Essalem 02000, Chlef, Algeria \\ ${ }^{2}$ Ecole Nationale Polytechnique, P.O Box 182, El Harrach, 16200, Algeria \\ "Corresponding author: g.henini@gmail.com
}

\begin{abstract}
This paper describes the development of a dynamic simulator model for a jacketed batch reactor equipped with a mono-fluid heating/cooling system. The Mono-fluid flows at constant flow-rate through the jacketed reactor. The heating and cooling are assured respectively by electrical resistance and two plate heat exchangers. A detailed description of the equations leading to the development of simulation model is presented. The model is based on writing the equations of the mass balance and the heat balance for the reactor and the thermal loop in unsteady state. To validate the simulation model, we first studied the thermal behavior of the reaction mixture during heating and cooling, using water as the reaction mixture. We then considered the consecutive chemical reaction of the synthesis of cyclopentanediol from cyclopentadiene by studying the yield of this reaction. The results show that heating the reaction mixture increases significantly the yield of this synthesis reaction.
\end{abstract}

Keywords: batch chemical reactor, thermal control, dynamic simulator, mono-fluid, heating/cooling system.

\section{INTRODUCTION}

Recent researches shows that dynamic process simulation is increasingly used in the pharmaceutical industry and the fine chemicals industries. Typically, these industries use batch processes, where exothermic reactions are involved. In such scenarios, the thermal behavior of the system has a strong influence on the reaction selectivity and the safety of the process. Therefore, the correct control of the reactor temperature is fundamental. The dynamic simulation allows researchers to study alternative equipment systems of heat transfer and chemical reactions. Its use extends more and more in these industries of chemicals of high added value ${ }^{1}$.

Process simulation is now a well-established technique and which is, frequently, used in many problems in process engineering. It makes it possible to deal with important issues such as risk reduction, improving the understanding of physical phenomena, sustainability knowledge, reducing costs by optimizing the performance or the reduction of time placing on the market of new products $^{2}$. In order for a simulator to be effective in all these areas, it is advisable that it uses models of knowledge (or phenomenological) constructed on the basis of the fundamental laws of physics and chemistry: the conservation equations (mass, energy, momentum), thermodynamics, kinetics, ... These equations have the advantage to provide a real prediction capacity in a domain of validity much more spread than the one for which data experiments are available.

However, the immediate advantage that can be expected to make an effective dynamic simulation in real processes is to verify the control strategy process. This is why the first industries that have incorporated dynamic simulation as a tool active were oil and refineries, where the control and preservation of production processes within a very small interval of operation provide a continuous stream of the product at a low added value type ${ }^{3-4}$. A dynamic simulation requires the simultaneous solution of algebraic and differential equations, so the adequate mathematical algorithms need to be incorporated into software. Such software has already the rigorous imple- mented model and mathematical algorithms ready to be used, which requires the user to enter the information relevant to chemical processes to study. In this context, the dynamic simulation becomes easy to use $\mathrm{e}^{4-5}$.

This work, thus, joins within the framework of the thermal conduct of multi-batch reactors used in industry of fine chemicals and specialties. The main tool for the implementation of chemical syntheses in the field of fine chemicals and pharmaceutical remains the batch reactor. The studies led to the elaboration of methodologies allowing the development of modus operandi adapted to the functional constraints and safety of these devices such as thermal control of batch reactors or fed-batch. However, these reactors, even if they offer features flexibility and versatility to present a number of technological limitations. In particular, poor conditions of evacuation of the heat released by chemical reactions pose a serious security problem.

The study in this paper aims to contribute to the development of a dynamic simulator for thermal control of a one-liter batch reactor equipped with a mono-fluid heating/cooling system. This system uses only one fluid for heating and cooling of the reactor contents. The heating and cooling are provided by the implementation on the thermal circuit of an electrical resistance and two heat exchangers of different cooling capacity.

\section{PROCESS DESCRIPTION}

A schematic diagram of the pilot plant is depicted in Fig. 1.

The experimental device consists of a one-liter jacketed glass reactor, fitted with a mono-fluid heating/cooling system. The mono-fluid used in this work is a mixture of ethylene glycol and water, in a ratio of $50 \%$ in weight, with a flow rate of $10001 \mathrm{~h}^{-1}$ and at a temperature which varies between -35 and $110^{\circ} \mathrm{C}$. The mono-fluid flow rate is measured by means of two flow-meters, one installed on the main thermal loop (Flow-meter 1) and the other on the secondary thermal loop (Flow-meter 2). The heating/ cooling system uses a $2000 \mathrm{~W}$ electrical resistance and two plate heat exchangers (PHE). One PHE uses cold 
water as a utility fluid at a temperature around $15^{\circ} \mathrm{C}$ and a maximum flow rate of $1500 \mathrm{l} \mathrm{h}^{-1}$, while the other uses a mixture of ethylene glycol and water, in a ratio of $50 \%$ in weight, at a temperature around $-10^{\circ} \mathrm{C}$ and a maximum flow of $1500 \mathrm{l} \mathrm{h}^{-1}$. The flow rates of the utility fluids are also measured. Three on-off valves allow the mono-fluid to be heated or cooled. Two other on-off valves are used to manipulate the utility fluids. A three-ways air-to-open valve ensures the division of the mono-fluid in two-parts during the cooling phases. A gearing pump ensures the circulation of the mono-fluid in the thermal loop at maximum flow rate of $1500 \mathrm{l} \mathrm{h}^{-1}$.

The reactor has the following physical specifications: an internal diameter of $82 \mathrm{~mm}$, a wall thickness of $9 \mathrm{~mm}$, an external jacket diameter of $125 \mathrm{~mm}$, a jacket wall thickness of $5 \mathrm{~mm}$, a maximal reactant mixture-reactor heat transfer area of $0.039 \mathrm{~m}^{2}$ and a jacket volume of $0.15 \mathrm{l}$. A propeller rotated at $260 \mathrm{rpm}$. The reactor is operated in batch and fed-batch modes. A piston pump allows the variation of the liquid reactant flow rate from 0 to $336 \mathrm{~cm}^{3} \mathrm{~h}^{-1}$.

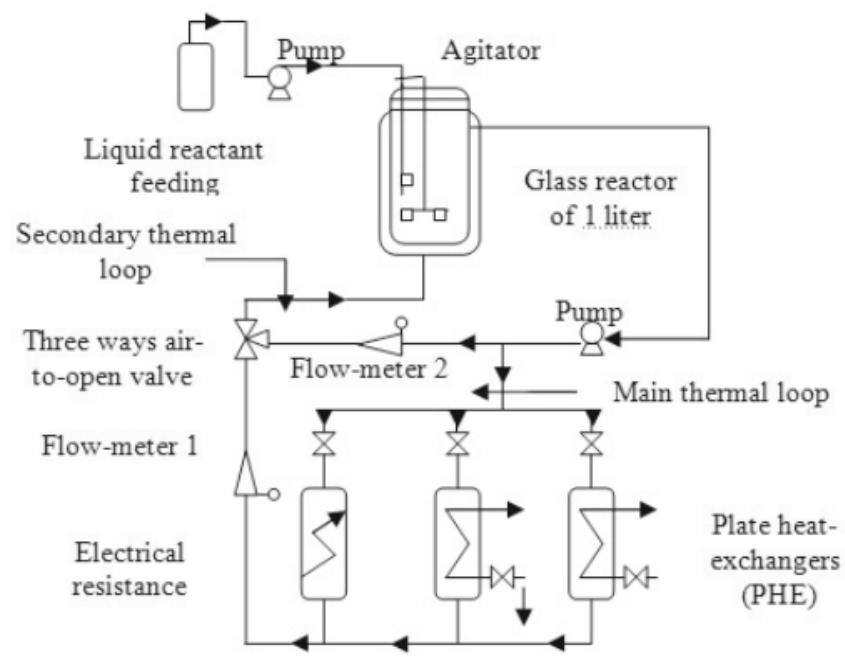

Figure 1. Pilot-plant of the reactor and its thermal environment

\section{PROCESS MODELING}

\section{Modeling of the reactor}

For a system involving nc species (subscript i) and nr reactions (subscript $\mathrm{j}$ ), the model has been established using the following assumptions:

- the reactor is perfectly mixed with homogeneous temperature in the reaction mixture;

- the physicochemical properties of each component of the reaction mixture are constant in the considered range of temperature, and the physical properties of the reaction mixture are revalued at each computation step as functions of temperature;

- feeding of the reactive is performed without volume concentration;

- the reactions are carried out in a pseudo-homogeneous liquid phase;

- the kinetic laws of the chemical reactions involved are assumed to be such that the reaction rate constant follows the Arrhenius law and the reaction rate is a function of the reactant concentrations.

For the reaction $\mathrm{j}$, the reaction rate is given by: $r_{j}=k_{j}^{0} \exp \left(-E_{j} / R T_{r}\right) \prod_{i=1}^{n c} C_{i}^{\alpha_{i j}}$

For each reaction, the activation energy $E_{j}$, the rate constant $k_{j}^{0}$, the partial orders $\alpha_{\mathrm{i}, \mathrm{j}}$ and the stoichiometric coefficients $C_{s}(i, j)(>0$ for products and $<0$ for reactants) have to be given. The dynamic simulation model is obtained by writing mass and heat balances for the reaction mixture, the reactor wall, the mono-fluid flowing inside the jacket and the jacket wall, electrical resistance, plate heat exchangers.

\section{MASS AND HEAT BALANCE ON THE REACTION MIXTURE}

A molar balance on each of the nc components yields nc differential equations:

$\frac{d n_{i}}{d t}=f_{c} x_{i}+\sum_{j=1}^{n r} C_{s}(i, j) r_{j} \frac{m_{r}}{\rho_{r}} 10^{3} \quad \mathrm{i}=1, \ldots \mathrm{nc}$

The mass of the reaction mixture is given by:

$m_{r}=\sum_{i=1}^{n c} n_{i} M_{i}$

The density of the reaction mixture $(\rho r)$ is estimated by assuming that the various components form a perfect mixture. The total volume $\frac{m_{r}}{\rho r}$ is equal to the sum of partial volumes, by:

$\frac{m_{r}}{\rho r}=\sum_{i=1}^{n c} \frac{n_{i} M_{i}}{\rho_{i}}$

i.e.:

$\frac{1}{\rho_{r}}=\sum_{i=1}^{n c} \frac{n_{i} M_{i}}{m_{r}} \cdot \frac{1}{\rho_{i}}$

Classical mixing laws give the physico-chemical properties of the mixture, according to:

$C p_{r}=\frac{1}{m_{r}} \sum_{i=1}^{n c} n_{i} M_{i} C p_{i}$

$\lambda_{r}=\frac{1}{m_{r}} \sum_{i=1}^{n c} n_{i} M_{i} \lambda_{i}$

$\mu_{r}^{\frac{1}{3}}=\frac{1}{m_{r}} \sum_{i=1}^{n c} n_{i} M_{i} \mu_{i}^{\frac{1}{3}}$

Values of $C p_{i}, \rho_{i}, \lambda_{i}$ and $\mu_{i}$ (properties of pure component i) are assumed to be constant over the range of considered temperatures, and are given as the data to the simulation model.

The heat balance on the reaction mixture gives the following differential equation:

$\frac{d\left(H_{r}\left(T_{r}\right)\right)}{d t}=-U_{r, p r} A_{r, p r}\left(T_{r}-T_{p r}\right)+f_{c} M_{c} H_{c}\left(T_{c}\right)$

Let us take as the basis for the enthalpy computation, the enthalpy of pure liquid component at temperature $T^{*}$. Then $\operatorname{Hr}\left(T_{r}\right)$ is expressed as:

$\operatorname{Hr}\left(T_{r}\right)=\sum_{i=1}^{n c} n_{i} M_{i} H_{i}\left(T_{r}\right)=\sum_{i=1}^{n c} n_{i} M_{i}\left[h_{f i}\left(T^{*}\right)+\int_{T^{*}}^{T_{r}} C p_{i}(T) d T\right]$

After development, the final expression is obtained:

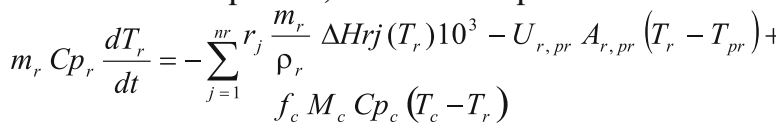

With : $\Delta H r\left(T_{r}\right)=\sum_{i=1}^{n c} M_{i}\left[h_{f i}\left(T^{*}\right)+C p_{i}\left(T_{r}-T^{*}\right)\right] C_{s}(i, j)$ 


\section{MODELLING OF THE JACKET}

The jacket is modelled by means of a succession of $\mathrm{N}$ tanks supposed perfectly stirred ( $\mathrm{N}$ being the number of tanks where the mono-fluid is in direct contact with the reactor wall and the jacket). The heat exchanges between the mono-fluid in the tank (i), the reactor wall, the wall of the jacket, the tank (i-1) and the tank $(i+1)$ are schematized in Fig. 2.

\begin{tabular}{|c|c|}
\hline \multicolumn{3}{|c|}{ Reaction mixture } \\
\hline \multicolumn{2}{|c|}{ Reactor wall } \\
\hline \\
\hline
\end{tabular}

Figure 2. Schematic of heat transfer in the tank (i) of the jacket

The heat balance on the mono-fluid in the tank (i) is given by the following equation:

$$
\begin{aligned}
& \frac{d\left(m_{f c}^{i} C p_{f c}^{i} T_{f c}^{i}\right)}{d t}=F_{f c}\left(\rho_{f c}^{i-1} C p_{f c}^{i-1} T_{f c}^{i-1}-\rho_{f c}^{i} C p_{f c}^{i} T_{f c}^{i}\right)+U_{p r, f c}^{i} \frac{A_{p r, f c}}{N}\left(T_{p r}-T_{f c}^{i}\right)+ \\
& U_{f c, p d e}^{i}\left(\frac{A_{f c, p d e}}{N}\right)\left(T_{p d e}-T_{f c}^{i}\right)
\end{aligned}
$$

With:

$m_{f c}^{i}=\rho_{f c}^{i}\left(\frac{V_{d e}}{N}\right)$

\section{HEAT BALANCE ON THE REACTOR WALL}

The Heat balance on this wall is defined by the following equation:

$\frac{d T_{p r}}{d t}=\frac{1}{m_{p r} C p_{p r}}\left[U_{r, p r} A_{r, p r}\left(T_{r}-T_{p r}\right)+U_{p r, e x t} A_{p r, e x t}\left(T_{e x t}-T_{p r}\right)+\sum_{i=1}^{N} U_{p r, f c}^{i}\left(\frac{A_{p r, f c}}{N}\right)\left(T_{f c}^{i}-T_{p r}\right)\right]$

\section{HEAT BALANCE ON THE JACKET WALL}

The jacket wall exchanges heat with mono-fluid, flowing inside the jacket and the ambient surroundings. A heat balance gives the following equation:

$\frac{d\left(m_{p d e} C p_{p d e} T_{p d e}\right)}{d t}=U_{p d e, e x t} A_{p d e, e x t}\left(T_{e x t}-T_{p d e}\right)+\sum_{i=1}^{N} U_{f c, p d e}^{i}\left(\frac{A_{f c, p d e}}{N}\right)\left(T_{f c}^{i}-T_{p d e}\right)$

\section{Modelling of the thermal loop}

\section{MODELLING OF HEATING PENCIL}

The heating pencil is formed of a steel stem inside which is placed an electrical resistance, the mono-fluid flows in an annular space formed by the stem and the electric resistance as shown in Fig. 3.

To model the heating pencil, we have considered the annular space as a stirred block in which the mono-fluid exchanges heat with the wall of the stem and receives a heat flow resulting from the electrical resistance.

a / Heat balance on the wall of the electrical resistance

The heat balance on this wall, which exchanges heat with the mono-fluid and instantly receives electric power, is given by the following equation:

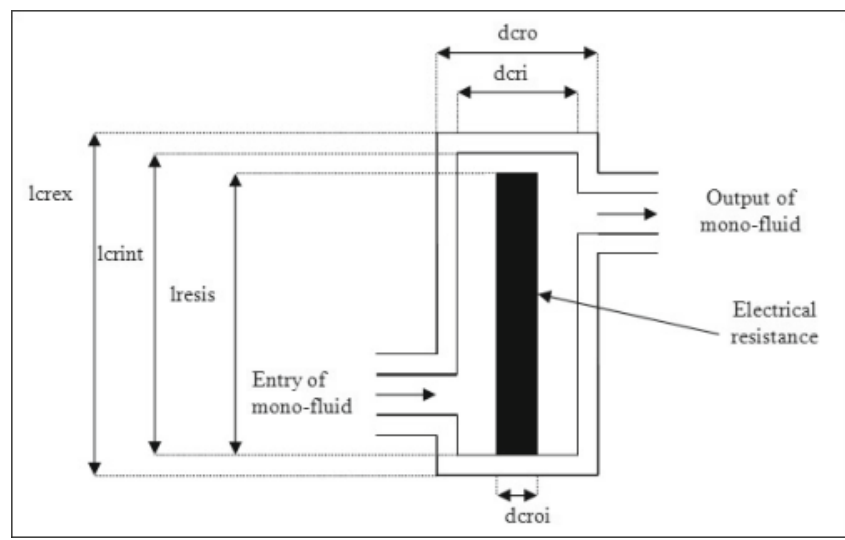

Figure 3. Simplified diagram of the electrical resistance

$\frac{d T_{\text {pres }}}{d t}=\left\{\frac{P_{\text {elec }}+U_{f c, \text { res }} A_{f c, \text { res }}\left(T_{c h}-T_{\text {pres }}\right)}{m_{\text {pres }} C p_{\text {pres }}}\right\}$

b / Heat balance on the mono-fluid

The balance of the mono-fluid involves the heat exchange with the walls of the electrical resistance and that of the stem and the amount of heat exchange between the input and the output of the tank is given by the following equation:

$\frac{d\left(m_{c h} C p_{c h} T_{c h}\right)}{d t}=F_{f c}\left(\rho_{c h}^{E} C p_{c h}^{E} T_{c h}^{E}-\rho_{c h} C p_{c h} T_{c h}\right)+U_{f c, p c h} A_{f c, p c h}\left(T_{p c h}-T_{c h}\right)+$

$U_{f c, \text { res }} A_{f c, \text { res }}\left(T_{\text {pres }}-T_{c h}\right)$

With: $m_{c h}=\rho_{c h} V_{c h}$

c / Heat balance on the wall of the stem

The heat balance on this wall which exchanges heat with mono-fluid and the ambient surroundings is given by the following equation:

$\frac{d T_{p c h}}{d t}=\left\{\frac{U_{p c h, e x t} A_{p c h, e x t}\left(T_{e x t}-T_{p c h}\right)+U_{f c, p c h} A_{f c, p c h}\left(T_{c h t}-T_{p c h}\right)}{m_{p c h} C p_{p c h}}\right\}$

\section{MODELLING OF PLATE HEAT EXCHANGERS}

Both heat exchangers used are plate heat exchangers (PHE). This type of exchanger is characterized especially for its good heat transfer. Seen their importance, several authors have contributed to the modelling of these exchangers ${ }^{6,7,8}$.

- Differential equations relative to the model of the heat exchanger

We consider a differential element of the plate heat exchanger which includes a volume element of the liquid and a volume element of the plate as shown in Fig. 4.

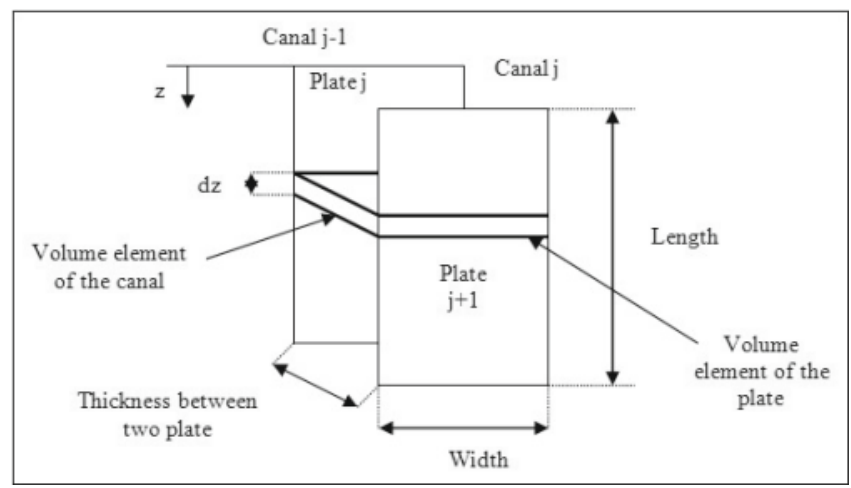

Figure 4. Modeling the flow of fluid between two plates 
Starting from the fundamental principle of conservation of thermal energy, the following equations describe the heat transfer between the fluid (mono-fluid or utility cooling) flowing through a channel $\mathrm{j}$ and two plates that cover:

$V_{j} \rho_{j} C p_{j}\left[\frac{\partial T_{j}}{\partial t}+n_{j} u_{x} \frac{\partial T_{j}}{\partial z}\right]=U_{j} A_{j+1}\left(T p_{j+1}-T_{j}\right)+U_{j} A_{j}\left(T p_{j}-T_{j}\right)$

For the plate $\mathrm{j}$ located between the two fluids (monofluid and cooling utility):

$V p_{j} \rho p_{j} C p p_{j} \frac{\partial T p_{j}}{\partial t}=U_{j} A_{j}\left(T_{j}-T p_{j}\right)+U_{j-1} A_{j}\left(T_{j-1}-T p_{j}\right)+V p_{j} \lambda p_{j} \frac{\partial^{2} T p_{j}}{\partial z^{2}}$

The main advantage of this model is that it allows to describe the mechanism of heat transfer inside the heat exchanger whatever the mode of arrangement chosen (in series, loop or complex) ${ }^{\mathbf{3}}$. As in our case the type of arrangement of the two fluids flow inside the heat exchanger loop is against the current.

Both derivatives can be expressed by discretization according to $\mathrm{z}$, what gives equations as the following ones:

$V_{j} \rho_{j} C p_{j}\left[\frac{d T_{j, i}}{d t}+\frac{n_{j} u_{z}}{\Delta z}\left(T_{j, i}-T_{j, i-1}\right)\right]=U_{j, i} A_{j+1, i}\left(T p_{j+1, i}-T_{j, i}\right)+$

$U_{j, i} A_{j, i}\left(T p_{j, i}-T_{j, i}\right)$

For the plate $\mathrm{j}$ :

$V p_{j} \rho p_{j} C p p_{j}\left[\frac{d T p_{j, i}}{d t}\right]=U_{j, i} A_{j, i}\left(T_{j, i}-T p_{j, i}\right)+U_{j-1, i} A_{j, i}\left(T_{j-1, i}-T p_{j, i}\right)+$

$\frac{V p_{j, i} \lambda p_{j}}{\Delta z^{2}}\left(T p_{j, i+1}-2 T p_{j, i}+T p_{j, i-1}\right)$

\section{MODELING PIPES}

a / Heat balance of the mono-fluid in each tank pipe $\mathrm{j}(\mathrm{j}=1, . ., 12)$

The heat balance translates the heat exchanges in the tank (i) of a pipe (j) between the mono-fluid and the wall of this pipe on one hand, and the tank (i) and the tank (i -1) on the other hand.

$m_{f c}^{i} C p_{f c}^{i} \frac{d T_{c o n d}^{i}}{d t}=U_{c o n d, p c o n d}^{i}\left(\frac{A_{c o n d, p c o n d}^{j}}{n^{j}}\right)\left(T_{\text {cond }}^{i}-T_{p c o n d}^{j}\right)+D_{f c} \rho_{f c}^{i-1} C p_{f c}^{i-1}$

$\left(T_{\text {cond }}^{i-1}-T_{\text {cond }}^{i}\right)$

With: $m_{f c}^{i}=\rho_{f c}^{i} \frac{V_{c o n d}^{j}}{n^{j}}$

b / Heat balance on the pipe wall $\mathrm{j}(\mathrm{j}=1, \ldots, ; 12)$

The heat balance on the wall of the pipe $j$, which exchanges heat with the mono-fluid and the ambient surroundings, is defined by the following equation:

$m_{\text {pcond }}^{j} C p_{\text {pcond }}^{j} \frac{d T_{\text {pcond }}^{j}}{d t}=\sum_{i=1}^{n c_{j}} U_{\text {cond, pcond }}^{j}\left(\frac{A_{\text {cond, pcond }}^{j}}{n^{j}}\right)\left(T_{\text {cond }}^{i}-T_{\text {pcond }}^{j}\right)+$

$U_{\text {ext,pcond }}^{j} A_{\text {ext,pcond }}^{j}\left(T_{\text {ext }}-T_{\text {pcond }}^{j}\right)$

\section{MODELLING OF THE THREE-WAY VALVE}

For its modelling, we consider that this valve is a mixture tank of two currents.

The heat balance is given by the following linear equation:

$F_{f c} \rho_{f c, m e l} C p_{f c, m e l}\left(T_{m e l}-T_{r e f}\right)=F_{f c}(1-\beta) \rho_{f c, n} C p_{f c, n}\left(T_{c o n d, n}{ }^{11}-T_{r e f}\right)+$

$F_{f c} \beta \rho_{f c, n^{10}} C p_{f c, n^{10}}\left(T_{c o n d, n^{10}}-T_{r e f}\right)$
From this balance, and taking as reference temperature $T_{r e f}$, the temperature at the outlet of the valve $T_{m e l}$, we obtain the following relation:

$T_{m e l}=\frac{(1-\beta) \rho_{f c, n^{11}} C p_{f c, n^{11}} T_{c o n d, n^{11}}+\beta \rho_{f c, n^{10}} C p_{f c, n^{10}} T_{c o n d, n^{10}}}{(1-\beta) \rho_{f c, n^{11}} C p_{f c, n^{11}}+\beta \rho_{f c, n^{10}} C p_{f c, n^{10}}}$

\section{STRATEGY FOR THE DIGITAL RESOLUTION}

Our model consists, on the one hand, of ordinary differential equations of

$$
18+n c+N+\sum_{i=1}^{12} n^{i}+2 \sum_{i=1}^{2}(2 . n p l a q u e-1) n t r c i
$$

differential variables (Mass and heat balances), and on the other, of algebraic equations (heat transfer coefficient, physical properties ....).

The strategy for solving such a problem, we chose the method of Gear. The principle of the Gear method is to transform the system of differential and algebraic equations into a system of nonlinear algebraic equation, ${ }^{\mathbf{9}} \mathbf{1 0}$.

\section{PROGRAMMING METHOD}

We used the Fortran language to simulate our model. The program is conversed in several modules or subroutines. The organizational dynamic simulation of thermal conduct of a batch reactor with jacket is given in Fig. 5 .

\section{VALIDATION OF THERMAL MODEL}

To validate the simulation model, we first studied the thermal behavior of the reaction mixture during heating and cooling, using water as the reaction mixture. We register the evolution of the temperature of the reaction mixture the inlet and outlet of the jacket over time. Then we examine the consecutive chemical reaction of the synthesis of cyclopentanediol from cyclopentadiene by studying the yield of this reaction. We record the changing concentrations of the constituents of the reaction mixture and the temperature thereof over time.

\section{Validation of the simulator with pure water}

These operations consist in introducing 0.7 liters of water into the reactor. The heating and the cooling begin after 120 seconds. For heating, we take powers of $1000 \mathrm{~W}$ and $2000 \mathrm{~W}$. For cooling, we take the same flow rates of mono-fluid in both heat exchangers with cold water and glycol water to $250 \mathrm{l} / \mathrm{h}$ and $750 \mathrm{l} / \mathrm{h}$. The evolutions of the temperatures of the reaction mixture (Tr) as well as in the input (Tede) and in the output (Tsde) of the jacket are shown in Figs. 6, 7 by heating simulations and in Figs. 8, 9, by the simulation of cooling in the case of the exchanger with cold water and finally in Figs. 10, 11 for the simulation of cooling by using the heat exchanger with glycol water.

From these simulation results of the heating and cooling of the reaction mixture which is pure water, several observations can be made available:

- For simulations of heating and cooling by the two exchangers, we notice the appearance of a transitional phase which operates the phenomenon of heating or cooling and that the temperature difference between the reaction mixture and the jacket is important, then we move towards an established regime where the tem- 


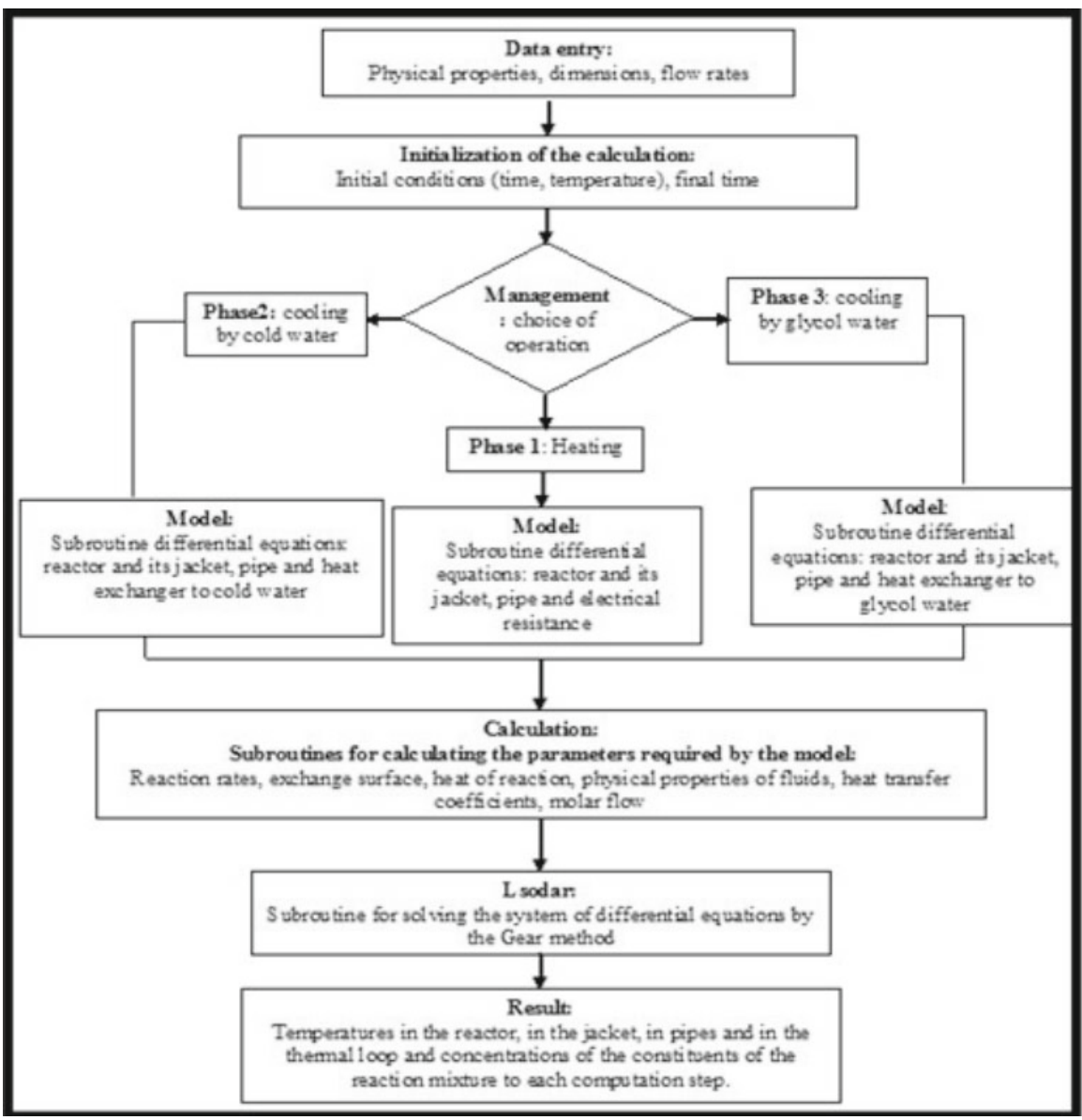

Figure 5. Flowchart of dynamic simulation of thermal conduct of a jacketed batch reactor

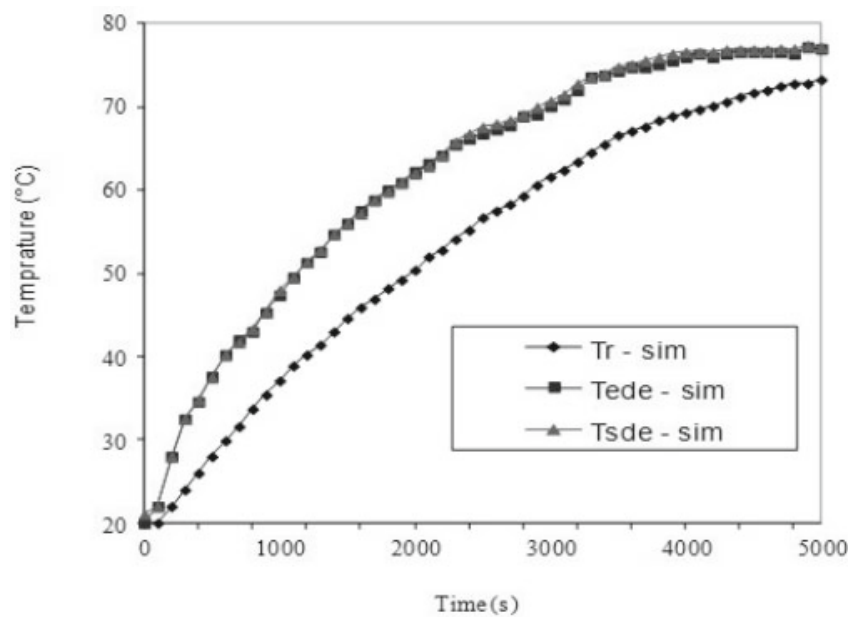

Figure 6. Simulation of heating of the pure water by $1000 \mathrm{~W}$

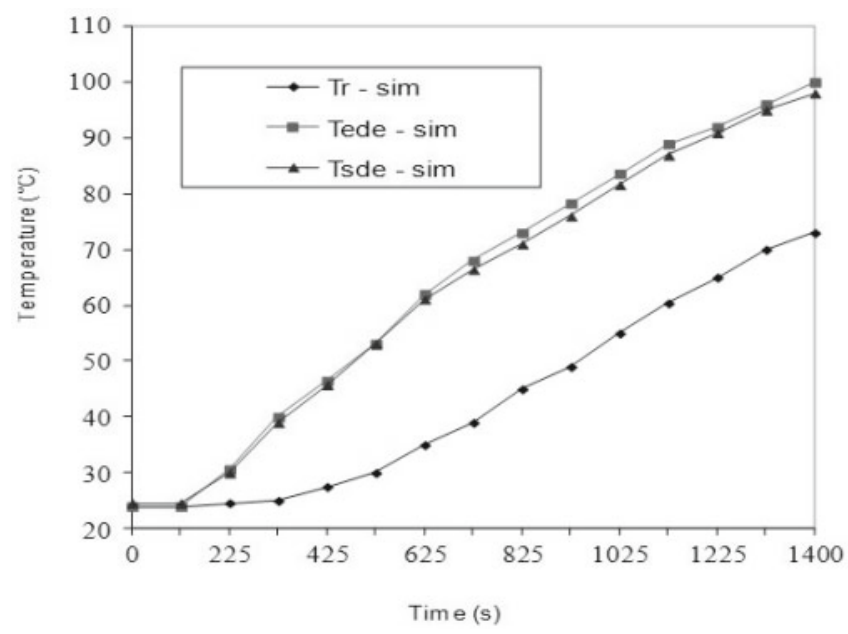

Figure 7. Simulation of heating of the pure water by $2000 \mathrm{~W}$

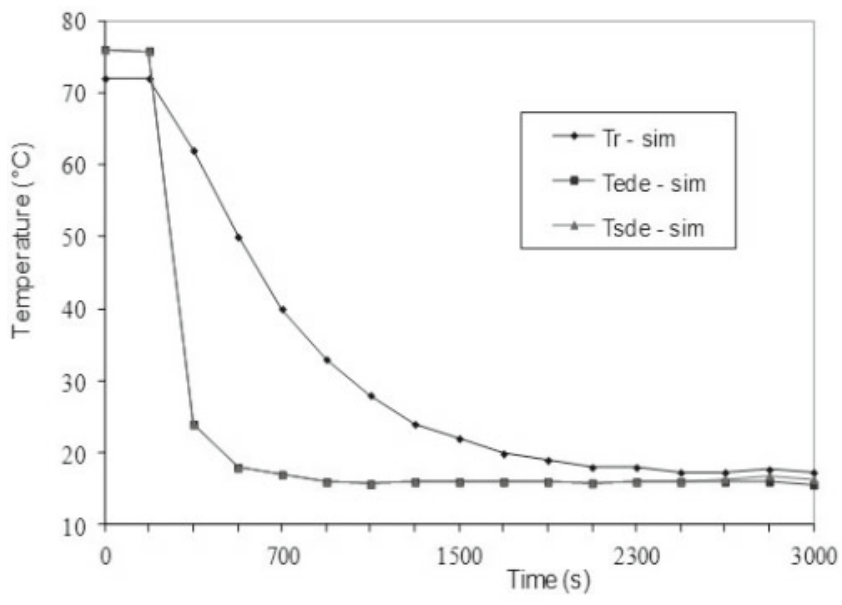

Figure 8. Simulation of cooling of the pure water by cold water to $250 \mathrm{l} / \mathrm{h}$

perature of the reaction mixture and the temperature of the jacket are very close. For example with heating by $1000 \mathrm{~W}$ the established regime is obtained at about 5000 seconds with a temperature of about $75^{\circ} \mathrm{C}$, Fig. 6;

- The operation of heating or cooling makes even faster as we increase the electric power for the heating (one gains around $15^{\circ} \mathrm{C}$ for an increase of $500 \mathrm{~W}$ ) and mono-fluid flow rate entering the heat exchanger for cooling.

- For cooling, the reaction mixture temperature decreases towards lower values with the glycol water heat exchanger than the heat exchanger with cold water because the temperature of the glycol water can be reduced to $-10^{\circ} \mathrm{C}$ while the temperature water achieves $15^{\circ} \mathrm{C}$.

- The difference in temperature between the reaction mixture and the inlet and outlet of the jacket increases 


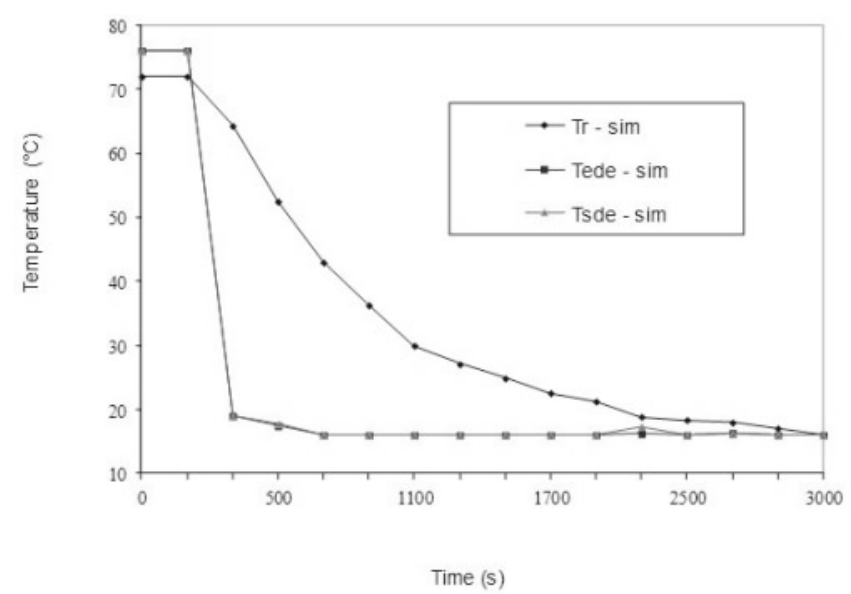

Figure 9. Simulation of cooling of the pure water by cold water to $750 \mathrm{l} / \mathrm{h}$

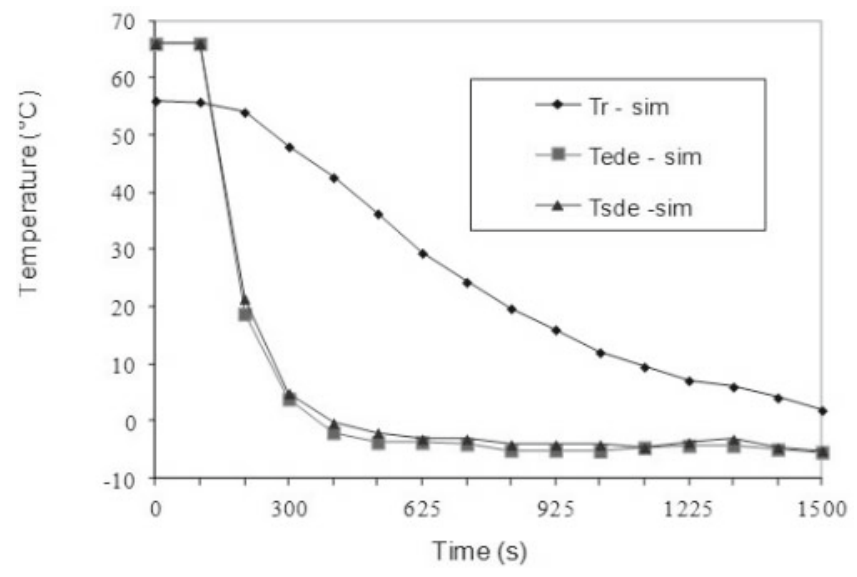

Figure 10. Simulation of cooling of the pure water by glycol water to $250 \mathrm{l} / \mathrm{h}$

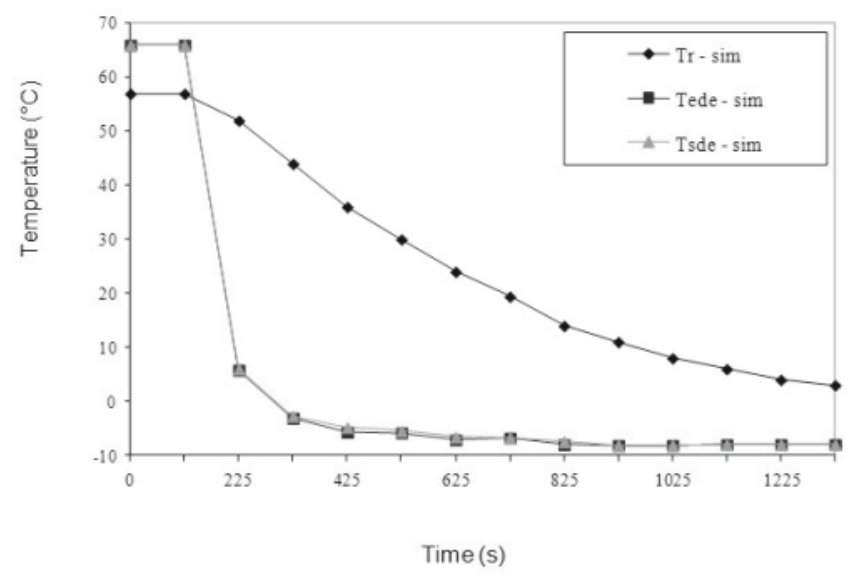

Figure 11. Simulation of cooling of the pure water by glycol water at $750 \mathrm{l} / \mathrm{h}$

gradually as one increases the power for heating and the flow rate of mono-fluid entering the heat exchanger for cooling. For example for the heating to 2000 seconds the gap is of about $9^{\circ} \mathrm{C}$ for the power of $1000 \mathrm{~W}$ and about $28^{\circ} \mathrm{C}$ for $2000 \mathrm{~W}$;

- For the heating by $2000 \mathrm{~W}$, we avoid to achieve the established regime in order not to exceed the boiling temperature of the mono-fluid which is glycol water $\left(110^{\circ} \mathrm{C}\right)$ and the boiling temperature of the reaction mixture which is pure water $\left(100^{\circ} \mathrm{C}\right)$ where the model with the assumptions introduced does not reflect the phenomenon existing in that case.
We compare our simulation results with the experimental results of Bouhenchir ${ }^{11,12}$, when heated by the power of 1000 and $2000 \mathrm{~W}$ of 0.7 liters of pure water injected into the reactor during the cooling by the heat exchanger with cold water with a flow rate of mono-fluid entering exchanger of 250 and $750 \mathrm{l} / \mathrm{h}$ and during the cooling by the heat exchanger with glycol water with a flow rate of the mono-fluid of 250 and $750 \mathrm{l} / \mathrm{h}$.

The comparison of simulation results and experiments for the three operations: heating, cooling by cold water and cooling by glycol water shows that our thermal model of simulation reproduces approximately the real dynamic behaviour of the reactor. However, we observe a slight difference especially at the beginning, which can be explained by the fact that the fluid temperature is experimentally stabilized after a while functioning time. In the results of Bouhenchir, one sees that the temperature changes even during the introduction of reagents we call time of casting. On the other hand, we cannot take this evolution by the simulator because we integrate after the entry of the cast. We notice a difference of $4^{\circ} \mathrm{C}$ during heating and $2^{\circ} \mathrm{C}$ during cooling between our results and the experimental results of Bouhenchir ${ }^{11,12}$ for the temperatures of the reaction mixture (Tr), the entry (Tede) and output (Tsde) of the jacket. The differences observed between our simulations and the experimental results of Bouhenchir can be linked to calculation errors resulting from the transformation of a continuous problem to problem discontinuous. On the other hand, it seems to us that we used correlations and expressions for calculating the physical properties of fluids and heat transfer coefficients different to those used by Bouhenchir ${ }^{11,12}$.

\section{Validation of the simulator with a chemical synthesis}

Another example of application of this simulator is the chemical synthesis of cyclopentanediol from cyclopentadiene which can be illustrated as follows:

$\mathrm{C}_{5} \mathrm{H}_{6}+\mathrm{H}_{2} \mathrm{O} \rightarrow \mathrm{C}_{5} \mathrm{H}_{7} \mathrm{OH}$

$\mathrm{C}_{5} \mathrm{H}_{7} \mathrm{OH}+\mathrm{H}_{2} \mathrm{O} \rightarrow \mathrm{C}_{5} \mathrm{H}_{8}(\mathrm{OH})_{2}$

$\mathrm{C}_{5} \mathrm{H}_{6} \rightarrow 0,5 \mathrm{C}_{10} \mathrm{H}_{12}$

The reactions are controlled by an Arrhenius law whose kinetic parameters are summarized in Table 1.:

Table 1. The kinetic parameters of the three synthesis reactions of cyclopentanediol ${ }^{13}$

\begin{tabular}{|l|c|c|c|}
\hline & Reaction (1) & Reaction (2) & Reaction (3) \\
\hline $\begin{array}{l}\text { Frequency factor } \\
\mathrm{k}_{\mathrm{j}}^{0}\left[\mathrm{I} \mathrm{mol}^{-1} \mathrm{~s}^{-1}\right]\end{array}$ & $3.575 \times 10^{8}$ & $3.575 \times 10^{8}$ & $2511.94 \times 10^{3}$ \\
\hline $\begin{array}{l}\text { Activation energy } \\
\mathrm{E}_{\mathrm{j}}\left[\mathrm{J} \mathrm{mol}^{-1}\right]\end{array}$ & 81.189 & 81.189 & 71.219 \\
\hline
\end{tabular}

The physical properties of the constituents involved in the three reactions are presented in Table 2.

To simulate well this reaction, we took two types of operations.

\section{SIMULATION WITH CASTING}

The principle of the first operation consists in introducing an initial load of $0.6 \mathrm{~kg}$ of water into the reactor in the ambient temperature then fed to the reactor by a casting of $0.2 \mathrm{~kg}$ of cyclopentadiene for 100 seconds at a temperature of $57^{\circ} \mathrm{C}$. 
Table 2. Physical parameters of the various constituents ${ }^{13}$

\begin{tabular}{|c|c|c|c|c|}
\hline & Cyclopenta-diene & Cyclopentanol & Cyclopentan-ediol & Dicyclopen-tadiene \\
\hline Molar mass $\mathrm{Mi}\left[\mathrm{kg} \mathrm{mol}^{-1}\right]$ & 0.066 & 0.084 & 0.102 & 0.132 \\
\hline Density $\rho_{i}\left[\mathrm{~kg} \mathrm{~m}^{-3}\right]$ & 934.2 & 934.2 & 934.2 & 934.2 \\
\hline Specific heat $C p_{i}\left[\mathrm{~kJ} \mathrm{~kg}^{-1} \mathrm{~K}^{-1}\right]$ & 3.0096 & 3.0096 & 3.0096 & 3.0096 \\
\hline Dynamic viscosity $\mu_{i}\left[\mathrm{~kg} \mathrm{~m}^{-1} \mathrm{~s}^{-1}\right]$ & 0.001 & 0.001 & 0.001 & 0.001 \\
\hline Thermal conductivity $\lambda_{i}\left[\mathrm{KJ} \mathrm{m}^{-1} \mathrm{~s}^{-1} \mathrm{~K}^{-1}\right]$ & $6.688 \times 10^{-4}$ & $6.688 \times 10^{-4}$ & $6.688 \times 10^{-4}$ & $4.18 \times 10^{-4}$ \\
\hline Molar enthalpy of formation at $25^{\circ} \mathrm{C} h_{, i}\left[\mathrm{~kJ} \mathrm{~mol}^{-1}\right]$ & -92.378 & -425.599 & -412.691 & -285.79 \\
\hline
\end{tabular}

The results obtained by the simulator in terms of evolution of the concentrations in the reaction mixture and the temperature during heating, during the cooling and without heating and cooling are presented in Figs. $12,13,14,15$.

From the three Figures 12, 13, 14 representing the evolution of the concentrations of constituents of the

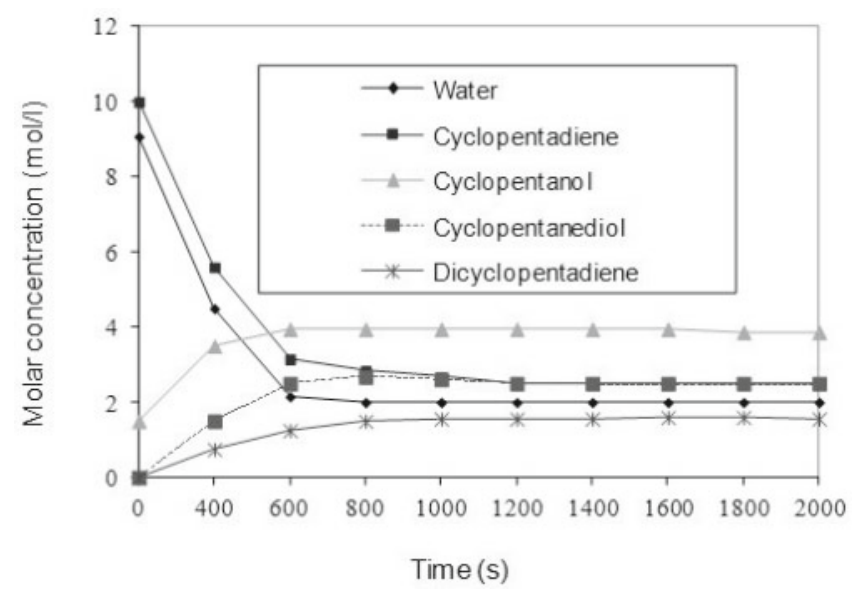

Figure 12. Simulation of heating the reaction mixture by 2000 Watt

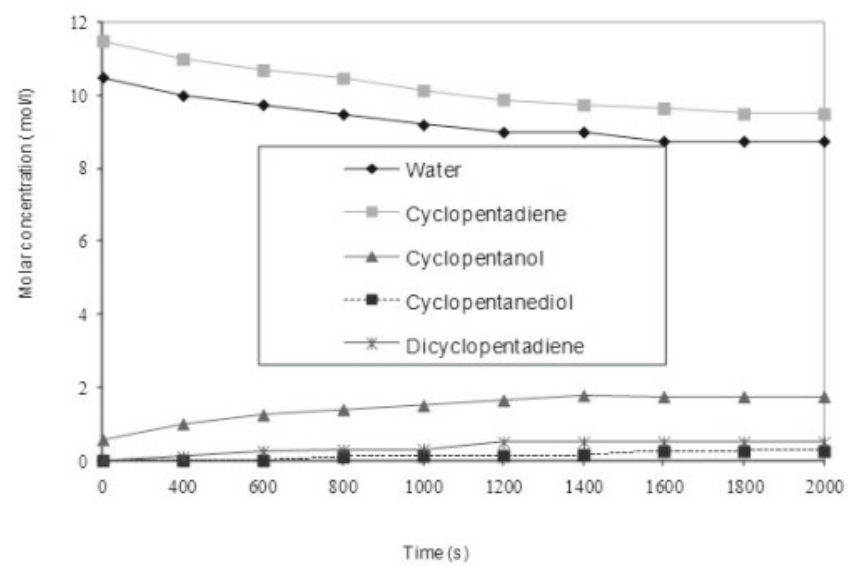

Figure 13. Simulation of cooling the reaction mixture by glycol water

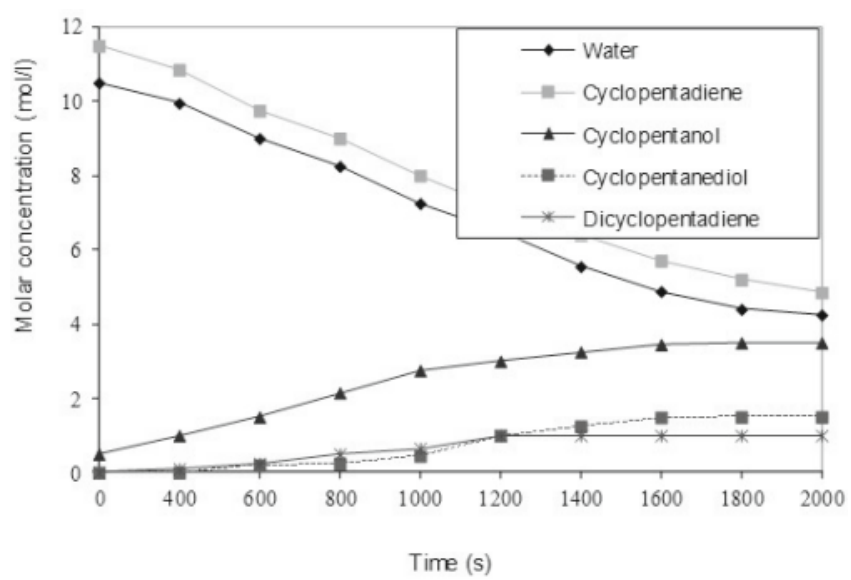

Figure 14. Simulation of the reaction mixture without heating and cooling

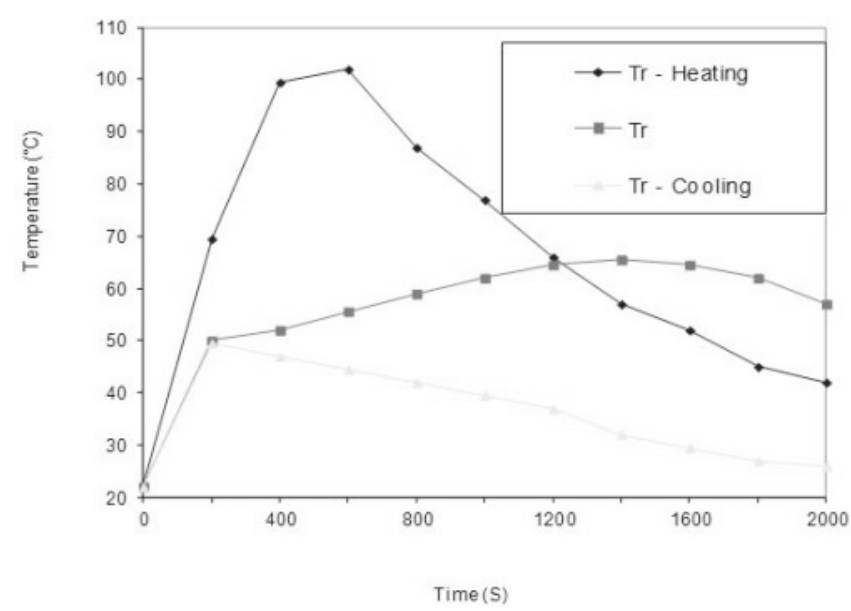

Figure 15. Comparison of temperatures of the reaction mixture during heating, during cooling and without these two operations

reaction mixture during the heating, cooling and without these two operations, we note that:

- The yield of cyclopentanol (the product of the first reaction) is of the order of $1.7 \mathrm{~mol} / \mathrm{l}$ for cooling, Fig. 13 , and $3.5 \mathrm{~mol} / \mathrm{l}$ without heating and cooling as shown in Fig. 14 and achieved 3.7 mol/l for heating, Fig. 12.

- The yield cyclopentanediol (the desired product by conversion of the cyclopentanol) is of the order of $1.5 \mathrm{~mol} / \mathrm{l}$ without heating and cooling Fig. 14, while it achieves $2.5 \mathrm{~mol} / \mathrm{l}$ for heating Fig. 12 .

- Appearance of the third reaction (produced unwanted), which occurs when the cylopentadiene is in excess.

- The three reactions are faster during the heating that can be achieved after about 800 seconds in Fig. 12, while without heating and cooling exceed 2000 seconds Fig. 14, whereas for cooling over 2000 seconds.

So we can say that the synthesis of cyclopentanediol from cylopentadiene is better and faster when heating the reaction mixture. One can see it clearly from Fig. 15 which shows a comparison between the evolution of the temperature of the reaction mixture during heating and cooling and without heating and cooling. We observe an increase of the temperature of the reaction in the three operations to reach $102^{\circ} \mathrm{C}$ during the heating. This point corresponds to a maximum conversion in the three reactions. This can be explained as follows: in the first reaction which is an endothermic reaction, the quantity of heat entrante with the cylopentadiene introduced in $57^{\circ} \mathrm{C}$ is consumed to produce cyclopentanol. As two other reactions are exothermic and as they take place at the same time as the first reaction, we observe a light increase in the reactor temperature which does not exceed the $57^{\circ} \mathrm{C}$ during cooling but which explains the low yield of these reactions when cooling. We have then a drop in the temperature of the reaction mixture even during heating because the temperature in the reactor exceeds the temperature of the mono-fluid in the jacket 
by effect of the two exothermic reactions. Therefore, there will be a heat exchange between the reactor and the jacket to achieve thermal equilibrium.

\section{SIMULATION WITHOUT CASTING}

The operation without casting consists in making load of the reactor by two reagents without casting. We tested a load of $0.6 \mathrm{~kg}$ of water and $0.2 \mathrm{~kg}$ of cyclopentadiene at $57^{\circ} \mathrm{C}$ then at $77^{\circ} \mathrm{C}$ then a load of equimolar $0.4 \mathrm{~kg}$ of water and $0.4 \mathrm{~kg}$ of cyclopentadiene to $57^{\circ} \mathrm{C}$. The simulations were performed with heating the reaction mixture by the power of 2000 watts. The results obtained by the simulator in terms of concentrations evolution in the reaction mixture and from the temperature during heating are presented in Figs. 16, 17, 18, 19, 20.

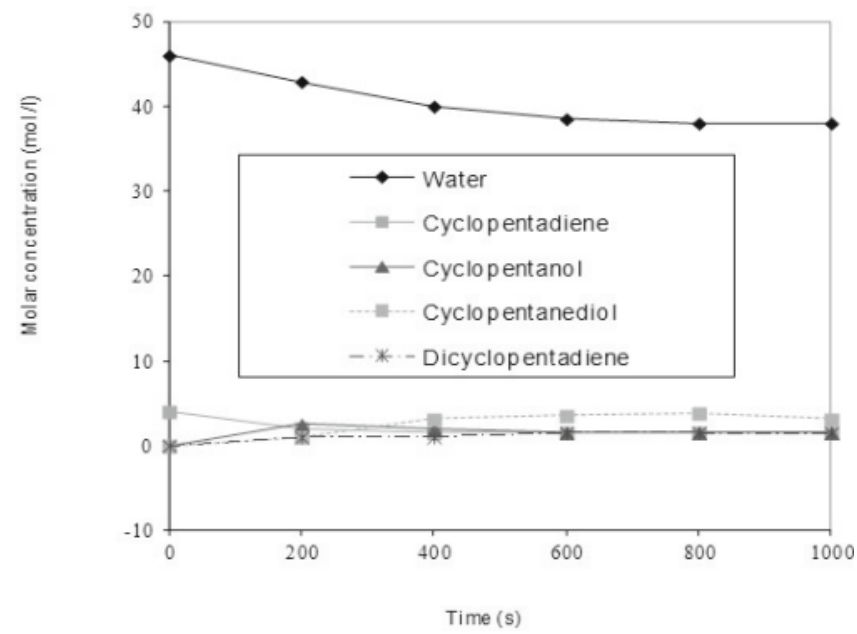

Figure 16. Simulation of heating the reaction mixture without casting reagents $57\left({ }^{\circ} \mathrm{C}\right)$

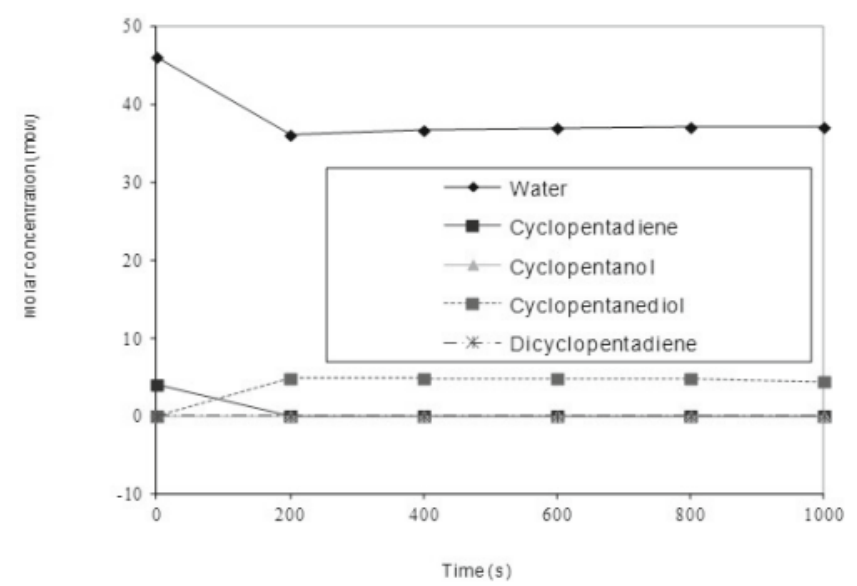

Figure 17. Simulation of heating the reaction mixture without casting reagents $77\left({ }^{\circ} \mathrm{C}\right)$

According to Figs. 16, 17 and 18 of evolution of the concentrations of the constituents of the reaction mixture without reagent casting at $57^{\circ} \mathrm{C}$ and $77^{\circ} \mathrm{C}$ and with a load of $0.6 \mathrm{~kg}$ of water and $0.2 \mathrm{~kg}$ of cyclopentadiene and in $57^{\circ} \mathrm{C}$ with an equimolar load $(0.4 \mathrm{~kg}$ of water and $0.4 \mathrm{~kg}$ of cyclopentadiene) by heating the reaction mixture, we notice the total conversion of cyclopentadiene in cyclopentanol for the three cases. We also notice a total conversion of cyclopentanol to cyclopentanediol in the case of equimolar reagents which gives approximately $8 \mathrm{~mol} / \mathrm{l}$ of cyclopentadiene and reagents for the case of non-equimolar in $77^{\circ} \mathrm{C}$ of the order of $4 \mathrm{~mol} / \mathrm{l}$. While

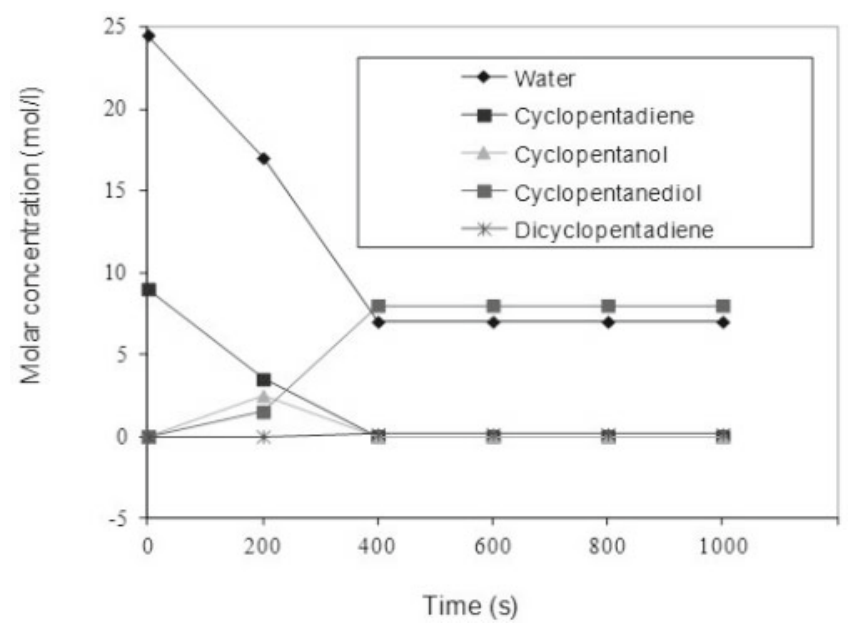

Figure 18. Simulation of heating the reaction mixture without casting reagents equimolar to $57\left({ }^{\circ} \mathrm{C}\right)$

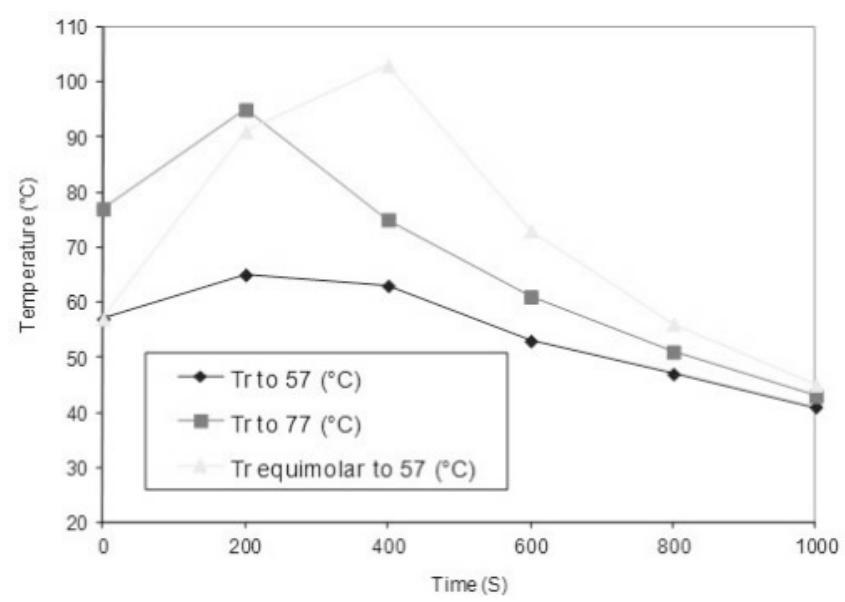

Figure 19. Comparison of temperatures of the reaction mixture without casting reagents

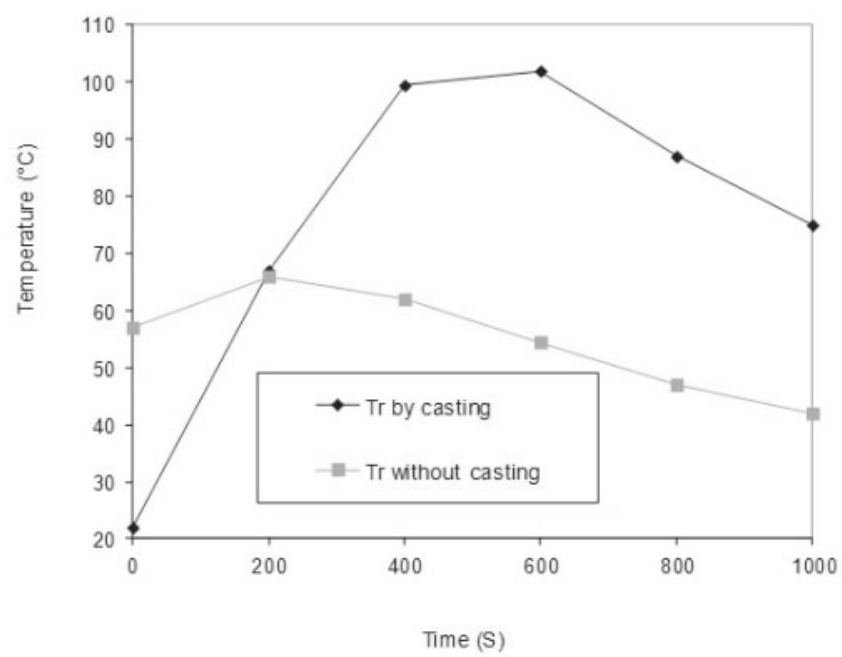

Figure 20. Comparison of temperatures during heating the reaction mixture with reagents casting and without casting $57\left({ }^{\circ} \mathrm{C}\right)$

in the case of non-equimolar reagents in $57^{\circ} \mathrm{C}$ we have a concentration of $3 \mathrm{~mol} / \mathrm{l}$ cyclopentanediol and the rest of the cyclopentanol of $1 \mathrm{~mol} / \mathrm{l}$. We also notice faster reactions by the simulation of heating without casting from the casting simulation with heating of reagent. We also see the absence of the intermediate reaction which is of for the total conversion of cyclopentadiene in cyclopentanol in the three figures. The comparison of the temperatures of these three cases in Fig. 19 shows 
that the good yield accompanies the highest maximum temperature because of the large amount of heat released during the second reaction.

\section{CONCLUSION}

This paper presents the development of a dynamic simulation model of batch chemical reactor. This model is based on writing the equations of the mass balance and the heat balance for the reactor and the thermal loop in unsteady state.

The validation of the simulator is an important step to test the performance of this simulator. In this article, validation was performed by two examples:

- The study of the thermal behavior of the reaction mixture during the heating and cooling water as reaction mixture. The validation showed that the simulator faithfully reproduces the real behavior of the process (5\% difference).

- The second validation is to introduce the chemical reactions of the synthesis of cyclopentanediol from cyclopentadiene in the reactor and study the yield of these reactions in simulations of heating and cooling the reaction mixture.

The results show that the heating of the reaction mixture significantly increases the yield of this synthesis reaction.

We can conclude that this synthesis will be better applied in a continuous reactor in a batch reactor, that due to the rapid reaction especially when heating the reaction mixture and reagents without casting. This conclusion can be considered as an advantage for our simulator to choose the suitable reactor for chemical synthesis. Chemical synthesis is a tool to validate our simulator and shows the importance of temperature control in a chemical reaction.

The simulator is a valuable tool that describes the dynamic evolution of the reactor and thus limits the number of experiments.

\section{NOMENCLATURE}

$A_{f c, p d e}$ heat transfer area between the mono-fluid and the jacket wall $\left(\mathrm{m}^{2}\right)$

$A_{p r f c} \quad$ heat transfer area between the mono-fluid and the reactor wall $\left(\mathrm{m}^{2}\right)$

$A_{f c, \text { res }}$ heat transfer area between the electrical resi stance wall and the mono-fluid $\left(\mathrm{m}^{2}\right)$

$A_{f c, p c h}$ heat transfer area between the mono-fluid and the stem wall $\left(\mathrm{m}^{2}\right)$

$A_{\text {pch, ext }}$ heat transfer area between the stem wall and the ambient surroundings $\left(\mathrm{m}^{2}\right)$

$A_{\text {cond,pcond }}^{j}$ heat transfer area between the mono-fluid and the pipe wall $\mathrm{j}\left(\mathrm{m}^{2}\right)$

$A_{\text {ext,pcond }}^{j}$ heat transfer area between the pipe wall $\mathrm{j}$ and the ambient surroundings $\left(\mathrm{m}^{2}\right)$

$A_{j}$ and $A_{j+1}$ heat transfer area of the plate j and j+1 $\left(\mathrm{m}^{2}\right)$

$C_{i} \quad$ concentration of component i (mol/l)

$C_{s}(i, j)$ stoichimetric coefficient of the component $\mathrm{i}$

$C p_{f c}^{i} \quad$ specific heat of the mono-fluid flowing inside the tank i $\left(\mathrm{KJ} \mathrm{Kg}^{-1} \mathrm{~K}^{-1}\right)$

$C p_{f c, \text { mel }}$ specific heat of the mono-fluid at the mixture temperature $\left(\mathrm{KJ} \mathrm{Kg}^{-1} \mathrm{~K}^{-1}\right)$
$C p_{p d e} \quad$ specific heat of the jacket wall $\left(\mathrm{KJ} \mathrm{Kg}^{-1} \mathrm{~K}^{-1}\right)$

$C p_{c h} \quad$ specific heat of the mono-fluid at the température $T_{c h}\left(\mathrm{KJ} \mathrm{Kg}^{-1} \mathrm{~K}^{-1}\right)$

$C p_{\text {pres }}$ average specific heat of the resistance wall $\left(\mathrm{KJ} \mathrm{Kg}^{-1} \mathrm{~K}^{-1}\right)$

$C p_{c h} \quad$ average specific heat of the wall of the stem $\left(\mathrm{KJ} \mathrm{Kg}^{-1} \mathrm{~K}^{-1}\right.$ )

$C p_{j} \quad$ specific heat of the fluid flowing inside the channel j $\left(\mathrm{KJ} \mathrm{Kg}^{-1} \mathrm{~K}^{-1}\right)$

$C p p_{j} \quad$ specific heat of the plate wall $\mathrm{j}\left(\mathrm{KJ} \mathrm{Kg}^{-1} \mathrm{~K}^{-1}\right)$

$C p_{\text {pcond }}$ specific heat of the pipe wall $\mathrm{j}\left(\mathrm{KJ} \mathrm{Kg}^{-1}{ }^{\circ} \mathrm{C}^{-1}\right)$

$D f_{c}$ molar flow rate of the mono-fluid $\left(\mathrm{m}^{3} \mathrm{~s}^{-1}\right)$

$E \quad$ index that represents the thermal state of mono-fluid at the inlet of the electrical resistance

$E_{j} \quad$ activation energy for the reaction $\mathrm{j}\left(\mathrm{J} \mathrm{mol}^{-1}\right)$

$f_{c} \quad$ liquid reactant feed molar flow rate $\left(\right.$ mole $\left.\mathrm{s}^{-1}\right)$

$F_{f c} \quad$ mono-fluid flow rate through the jacket $\left(\mathrm{m}^{3} \mathrm{~s}^{-1}\right)$

$k_{j}^{0} \quad$ rate constant for reaction $\mathrm{j}$

$M_{i} \quad$ molar mass of component i $\left(\mathrm{Kg} \mathrm{mol}^{-1}\right)$

$m_{c h} \quad$ mass of mono-fluid present in the jacket of the electrical resistance $(\mathrm{Kg})$

$m_{f c}^{i} \quad$ mass of the mono-fluid present in the tank $\mathrm{i}$ of the pipe $\mathrm{j}(\mathrm{Kg})$

$m_{\text {pde }} \quad$ mass of the jacket wall $(\mathrm{Kg})$

$m_{\text {pres }}$ mass of the electrical resistance wall $(\mathrm{Kg})$

$m_{\text {pcond }}^{j} \quad$ mass of the pipe wall $\mathrm{j}(\mathrm{Kg})$

$m_{p c h} \quad$ total mass of the stem wall $(\mathrm{Kg})$

$\mathrm{N}$ number of tanks of the jacket

$n_{c} \quad$ number of components present in the reaction mixture

$n_{i} \quad$ number of moles for component $\mathrm{i}$

$n_{j} \quad$ index which indicates the direction of fluid flow in the channel $\mathrm{j}$ (plate heat exchangers)

$n$ number of reactions

$P_{\text {elec }} \quad$ electrical power value $\left(\mathrm{KJ} \mathrm{s}^{-1}\right)$

$R \quad$ perfect gas constant $\left(\mathrm{R}=8,32 \mathrm{~J} \mathrm{~mol}^{-1} \mathrm{~K}^{-1}\right)$

$r_{j} \quad$ rate of the reaction $\mathrm{j}\left(\mathrm{mol} \mathrm{l}^{-1} \mathrm{~s}^{-1}\right)$

$T_{r} \quad$ reaction mixture temperature $\left({ }^{\circ} \mathrm{C}\right)$

$T_{f c}^{i} \quad$ temperature of the mono-fluid in the tank $\mathrm{i}$ of the jacket $\left({ }^{\circ} \mathrm{C}\right)$

$T_{c h}$ temperature of mono-fluid in the tank $\left({ }^{\circ} \mathrm{C}\right)$

$T_{\text {cond }} i$ temperature of mono-fluid in the tank $\mathrm{i}\left({ }^{\circ} \mathrm{C}\right)$

$T_{\text {cond, } n^{11}}$ and $T_{\text {cond, } n^{10}}$ mono- fluid temperature in the latter tanks of two pipes 10 and $11\left({ }^{\circ} \mathrm{C}\right)$

$T_{\text {pcond }}^{j} \quad$ pipe wall $\mathrm{j}$ temperature $\left({ }^{\circ} \mathrm{C}\right)$

$T_{j} \quad$ temperature of the fluid flowing in the channel j $\left({ }^{\circ} \mathrm{C}\right)$

$T_{j-1} \quad$ temperature of the fluid flowing in the channel $\mathrm{j}-1\left({ }^{\circ} \mathrm{C}\right)$

$T_{p j} \quad$ plate $\mathrm{j}$ temperature $\left({ }^{\circ} \mathrm{C}\right)$

$T_{p j+1} \quad$ plate $\mathrm{j}+1$ temperature $\left({ }^{\circ} \mathrm{C}\right)$

$T_{\text {pres }} \quad$ electrical resistance wall temperature $\left({ }^{\circ} \mathrm{C}\right)$

$T_{p c h} \quad$ stem wall temperature $\left({ }^{\circ} \mathrm{C}\right)$

$T_{\text {mel }} \quad$ mixing temperature at the outlet of the three-way valve $\left({ }^{\circ} \mathrm{C}\right)$

$T_{\text {ref }} \quad$ reference temperature $\left({ }^{\circ} \mathrm{C}\right)$

$U_{\text {cond,pcond }}^{j}$ heat transfer coefficient between the mono-fluid and the pipe wall $\mathrm{j}$ in the tank $\mathrm{i}\left(\mathrm{KJ} \mathrm{m}^{-2} \mathrm{~s}^{-1}{ }^{\circ} \mathrm{C}^{-1}\right)$

$U_{\text {ext,pcond }}^{j}$ heat transfer coefficient between the pipe wall $\mathrm{j}$ and the ambient surroundings $\left(\mathrm{KJ} \mathrm{m}^{-2} \mathrm{~s}^{-1}{ }^{\circ} \mathrm{C}^{-1}\right)$ 
$U_{p r, f c}^{i} \quad$ heat transfer coefficient between the reactor wall and the mono-fluid in the tanks $\mathrm{i}\left(\mathrm{KJ} \mathrm{m}^{-2}\right.$ $\mathrm{s}^{-1}{ }^{\circ} \mathrm{C}^{-1}$ )

$U_{p d e, \text { ext }}$ heat transfer coefficient between the jacket wall and the ambient surroundings $\left(\mathrm{KJ} \mathrm{m}^{-2} \mathrm{~s}^{-1}{ }^{\circ} \mathrm{C}^{-1}\right)$

$U_{f c \text {, res }}$ heat transfer coefficient between the mono-fluid and the electrical resistance wall $\left(\mathrm{KJ} \mathrm{m}^{-2} \mathrm{~s}^{-1}{ }^{\circ} \mathrm{C}^{-1}\right)$

$U_{f c, p c h}$ heat transfer coefficient between the mono-fluid and the stem wall $\left(\mathrm{KJ} \mathrm{m}^{-2} \mathrm{~s}^{-1}{ }^{\circ} \mathrm{C}^{-1}\right)$

$U_{p c h \text {, ext }}$ heat transfer coefficient between the stem wall and the ambient $\left(\mathrm{KJ} \mathrm{m}^{-2} \mathrm{~s}^{-1}{ }^{\circ} \mathrm{C}^{-1}\right)$

$U_{j} \quad$ heat transfer coefficient between the mono-fluid and the plate $\mathrm{j}\left(\mathrm{KJ} \mathrm{m} \mathrm{m}^{-2} \mathrm{~s}^{-1}{ }^{\circ} \mathrm{C}^{-1}\right)$

$U_{j-1} \quad$ heat transfer coefficient between the mono-fluid and the plate $\mathrm{j}-1\left(\mathrm{KJ} \mathrm{m}^{-2} \mathrm{~s}^{-1}{ }^{\circ} \mathrm{C}^{-1}\right)$

$u_{z} \quad$ mono- fluid flow velocity $\left(\mathrm{m} \mathrm{s}^{-1}\right)$

$V_{c h} \quad$ volume of the tank occupied by the mono-fluid $\left(\mathrm{m}^{3}\right)$

$V_{\text {cond }}^{j} \quad$ volume of the pipe $\mathrm{j}\left(\mathrm{m}^{3}\right)$

$V_{\text {pres }} \quad$ volume of the jacket $\left(\mathrm{m}^{3}\right)$

$V_{j}$ retention volume in the channel $\mathrm{j}\left(\mathrm{m}^{3}\right)$

$V_{\text {pcond }}^{j} \quad$ volume of the pipe wall $\mathrm{j}\left(\mathrm{m}^{3}\right)$

$V_{\text {pres }} \quad$ volume of the electrical resistance wall $\left(\mathrm{m}^{3}\right)$

$V p_{j} \quad$ volume of the plate wall $\mathrm{j}\left(\mathrm{m}^{3}\right)$

$x_{i} \quad$ molar fraction of component $\mathrm{i}$

\section{Greek characters}

$\alpha_{i j} \quad$ partial order of component $\mathrm{i}$ for the reaction $\mathrm{j}$

$\beta \quad$ fraction of the mono-fluid flow rate which must pass through the heat exchange

$\lambda p_{j} \quad$ thermal conductivity of the plate $\mathrm{j}\left(\mathrm{KJ} \mathrm{m}^{-1} \mathrm{~s}^{-1}\right.$ $\mathrm{K}^{-1}$ )

$\rho_{c h}$ density of the mono-fluid at the temperature $T_{c h}\left(\mathrm{Kg} \mathrm{m}^{-3}\right)$

$\rho_{f_{c}}^{i} \quad$ density of the mono-fluid in the tank $\mathrm{i}\left(\mathrm{Kg} \mathrm{m}^{-3}\right)$

$\rho_{f c, m e l}$ density of the mono-fluid at the mixture temperature $\left(\mathrm{Kg} \mathrm{m}^{-3}\right)$

$\rho_{j} \quad$ density of the fluid flowing in the channel $\mathrm{j}$ $\left(\mathrm{Kg} \mathrm{m}^{-3}\right)$

$\rho_{d e} \quad$ density of the jacket wall $\left(\mathrm{Kg} \mathrm{m}^{-3}\right)$

$\rho p_{j} \quad$ density of the plate wall $\mathrm{j}\left(\mathrm{Kg} \mathrm{m}^{-3}\right)$

$\rho_{\text {cond }} \quad$ density of the pipe wall $\left(\mathrm{Kg} \mathrm{m}^{-3}\right)$

\section{LITERATURE CITED}

1. Dirion, J.L., Cabassud, M., Casamatta, G. \& Le Lann, M.V. (2002). Neural Networks for Process Control: Application to the Temperature Control of Batch Chemical Reactors. Vol. 2, (pp 444-450). Expert System, by Academic Press.

2. Baudoin, O., Baudet, P., Dechelotte, S. \& Hameury, G. (2004). Using the software Batch Reactor for a safety study in the context of exothermic reactions (June 28). Prosim S.A: Press release.

3. Bouhenchir, H., Cabassud, M., Le Lann, M.V. \& Casamatta G. (2001). A general simulation model and a heating/cooling strategy to improve controllability of batch reactors. Trans IchemE. 79, Part A, 641-646. DOI: $10.1205 / 026387601316971217$.

4. Josep, A., Felliu, Iban Grau, Miquel A. Alos, Jose, J. \& Macias-Hernandez (2003). Match Your Process
Constraints Using Dynamic Simulation. December, (pp. 42-43). Information Technology C.E.P.

5. Uhlemann, J., Cabassud, M. \& Le Lann M.V. (1994). Semi-Batch reactor optimization and control for the epoxidation of furfural. Chem. Eng. Sci. 49 (18), 3169-3191. DOI: 10.1016/0009-2509(94)E0088-8.

6. Georgiadis, M.C., Rotstein, G.E. \& Macchietto, S. (1998). Modeling and simulation of Shell and Tube Heat Exchangers under Milk Fouling. AICHE J. 44 (4), 959-971. DOI: 10.1002/aic.690440422.

7. Bahaidarah, H.M.S., Anand, N.K. \& Chen, H.C. (2005). Numerical Study of Heat and Momentum Transfer in Channels with Wavy Walls. Numerical Heat Transfer, Part A, 47 (5), 417-439. DOI: 10.1080/10407780590891218.

8. Bahaidarah, H.M.S., Ijaz, M. \& Anand, N.K. (2006). Numerical Study of Fluid Flow and Heat Transfer over a Series of In-line Non-circular Tubes confined in a Parallel Plate Channel. Numerical Heat Transfer, Part B, 50, 97-119. DOI: 10.1080/10407790600599041.

9. Hindmarsh, A.C. (1980). LSODE and LSODI, Two new initial value ordinary differential equation solvers. ACM Signum Newsletter, 15 (4), 10-11. DOI > 10. 1145/1218052.1218054.

10. Gear, C.W. \& Osterby, O. (1984). Solving ordinary differential equations with discontinuities. ACM Transaction on Mathematical Software, 10 (1), 23-44. DOI > 10. $1145 / 356068.356071$.

11. Bouhenchir, H. (2000). Implementation of predictive control for conducting heat from a batch reactor equipped with a mono-fluid. PhD Thesis, ENSIGC Toulouse, France.

12. Bouhenchir, H., Cabassud, M., Le Lann, M.V. \& Casamatta G. (2000). A heating-cooling management to improve controllability of batch reactor equipped with a mono-fluid heating-cooling system. European Symposium on Computer Aided Process Engineering (ESCAPE-10), 7-10 May, 2000, Florence-Italy, Computer-Aided Chemical Engineering, 8, 601-606. DOI: 10.1016/ S1570-7946(00)80102-9.

13. Bouhenchir, H. (2005). Team fine chemical processes. Laboratory of Chemical Engineering at ENSIACET of Toulouse. 